Criação/ Exposição de Artes 


\section{Transeuntes \\ América Latina}

Elza AJZENBERG*

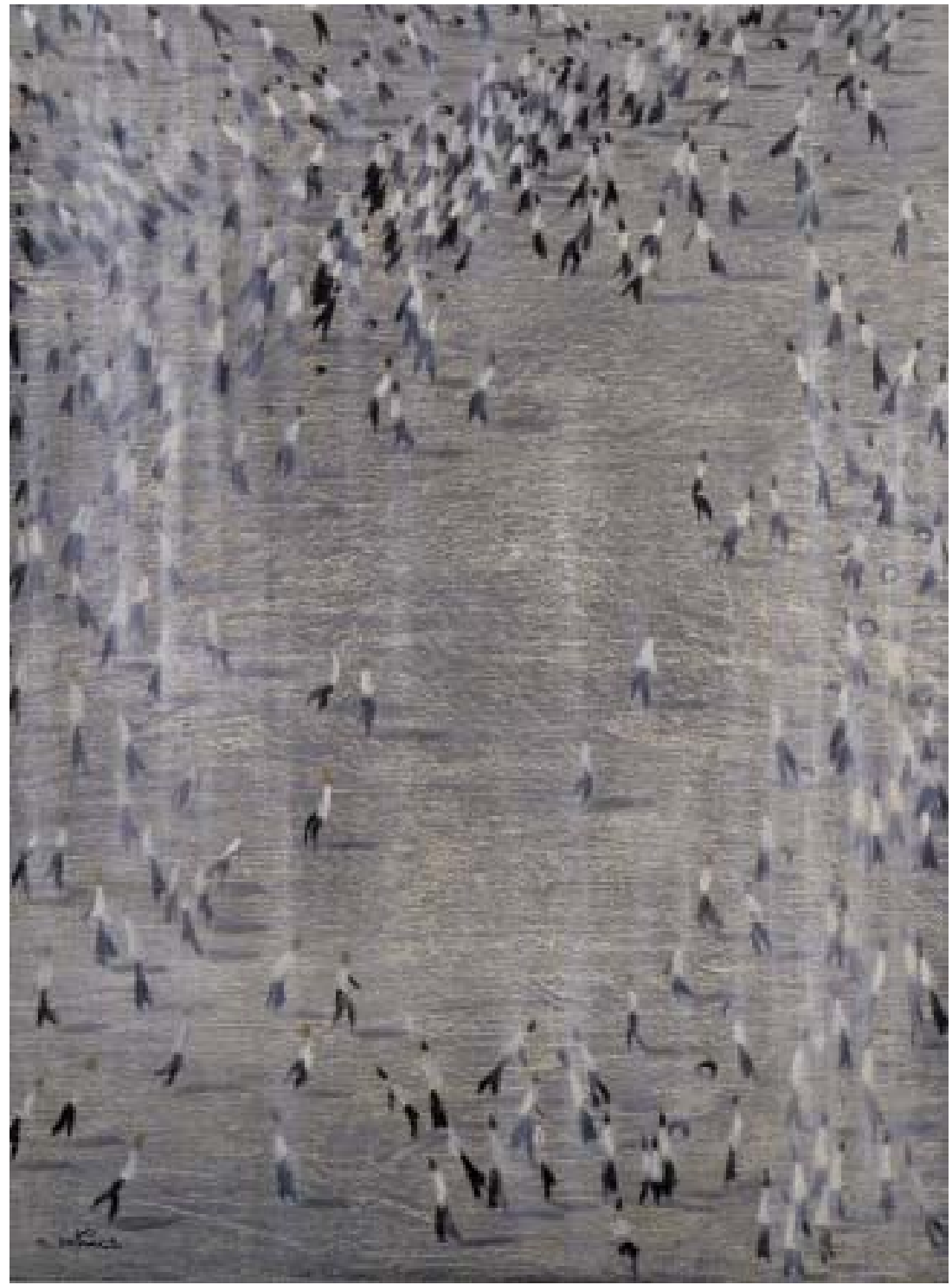

Nemesio ANTúNEZ (Santiago, Chile, 1918-1993), Os Transeuntes, 1954.

* Título da Exposição apresentada pelo MAC-USP (Museu de Arte Contemporânea da Universidade de São Paulo), em sua sede na Cidade Universitária (Rua da Reitoria, 160), no período de 29 de setembro a 15 de novembro de 2005, com a curadoria e texto de Elza Ajzenberg. 


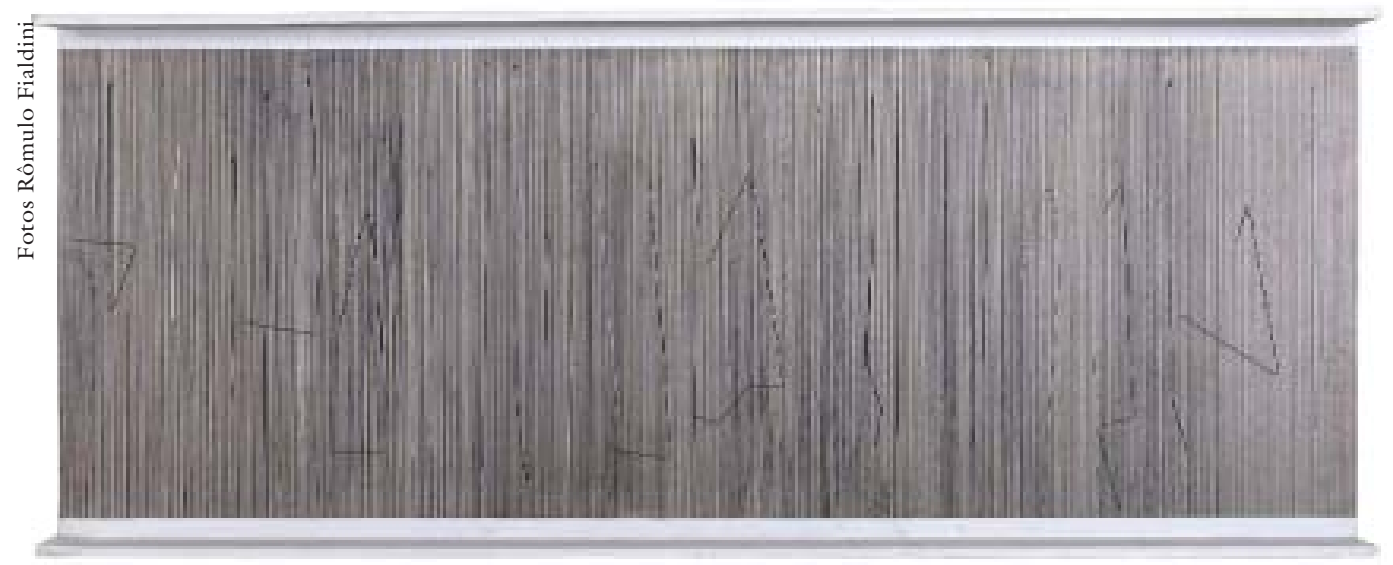

Jesús R. SOTO (Ciudad Bolívar, Venezuela, 1923 - Paris, França, 2005), Vibração, 1963.

\begin{abstract}
EXPosição TRANSEUNTES tem como referência a obra de Nemésio An$A$ tunes. É fruto do esforço concentrado de pesquisadores e técnicos do 1 Museu de Arte Contemporânea da Universidade de São Paulo (MAC USP), juntamente com o Corpo Consular da América Latina. Objetiva refletir sobre as metáforas plásticas de artistas modernos e contemporâneos, atentos às transformações de seu tempo. Apresenta como eixos para reflexão: "Buscas de Identidade"; "Lutas, Sonhos e Utopias" e "Entre Rupturas e Conjugações".
\end{abstract}

Os pequenos personagens que integram a obra de Nemésio Antunes instigam aos questionamentos: De onde viemos? Quem somos? Para onde vamos?

Ao refletir sobre a arte da América Latina é preciso TRANSITAR por caminhos que remetem a vários históricos distintos e que se confrontam cotidianamente.

Com a chegada dos europeus, a América, de certo modo, perdeu a identidade e ganhou outras. Os séculos de colonização acrescentaram novos elementos culturais que motivaram buscas incessantes.

Existe um eixo latino-americano? Pergunta difícil de ser respondida sem cair em um essencialismo. Há uma idéia de América Latina como fonte de sonhos e utopias, unindo geografia, história, língua e religião, compartilhada por diversos artistas e escritores. Porém, a experiência colonizadora conduziu à luta pela independência e à busca de identidades políticas e culturais próprias de cada país.

Dos habitantes originais da América - antigas civilizações e as denominadas populações indígenas -, alguns continuam a existir, mesmo vivendo dentro de territórios cujas divisões não necessariamente correspondem às fronteiras dos países criados pós-independência.

Hoje o antigo esplendor de várias dessas culturas é pouco mais do que uma recordação, pois séculos de destruição militar e cultural reduziram essas populações a uma fração do que eram.

Ainda hoje, a América procura sua identidade. Países caminham lado a lado, esbarrando-se nos percalços da História, mas continuam desconhecidos entre 
si e vivem no embate de não serem índios, não serem negros, não serem brancos, sendo todos ao mesmo tempo.

“América Latina” é, claramente, uma designação de sentido político e cultural. Compreende países da América do Sul, América Central, Caribe, Antilhas e México. Origina-se no contexto da política externa francesa dos anos de 1850, para referir-se às terras que haviam sido colônias espanholas, portuguesas e francesas.

A noção de América Latina como um "não-lugar", a partir do qual é possível elaborar uma alternativa crítica, inscreve uma metáfora, expressando suas buscas, utopias e desencontros. Surge também em razão das rupturas estéticas promovidas no século XX.

O período de 1920 a 1940 é considerado como um momento fundamental para a arte latino-americana moderna. Marca o regresso à Europa de precursores e notáveis expoentes da vanguarda histórica. Regresso motivado pela urgência de transformar em realidade a promessa da arte contemporânea colocar-se ao alcance da sociedade em processo de modernização.

O período de 1950 a 1970 é produto do impulso modernizador e desenvolvimentista provocado pelas conseqüências da Segunda Guerra Mundial. Pode-se considerar como o momento de maior expansão e internacionalização da arte latino-americana.

Essa maturidade se manifesta em uma seqüência de "rupturas radicais", tanto de artistas, como de grupos que defendem maior autonomia frente às imposições de modelos artísticos. Coexistem: releituras estéticas envolvendo as ambigüidades do crescimento urbano; projetos de resistência decorrentes das contradições sociopolíticas; obras interativas e propostas conceituais.

O final desse período, por sua vez, apresenta um contexto crítico. Recrudecimento de regimes autoritários, perseguições a intelectuais, artistas e lideranças políticas, constituem golpe fatal para os projetos em curso. O desenlace desses eventos assinala o questionamento de utopias e da ação revolucionária vanguardista, com desdobramentos sobre as questões estéticas no início do século XXI.

São Paulo, setembro de 2005.

Elza Ajzenberg é diretora do Museu de Arte Contemporânea da Universidade de São Paulo e professora da Escola de Comunicações e Artes da USP. @ - majzenberg@uol.com.br Texto recebido em 10.10.05 e aceito em 17.10.05. 


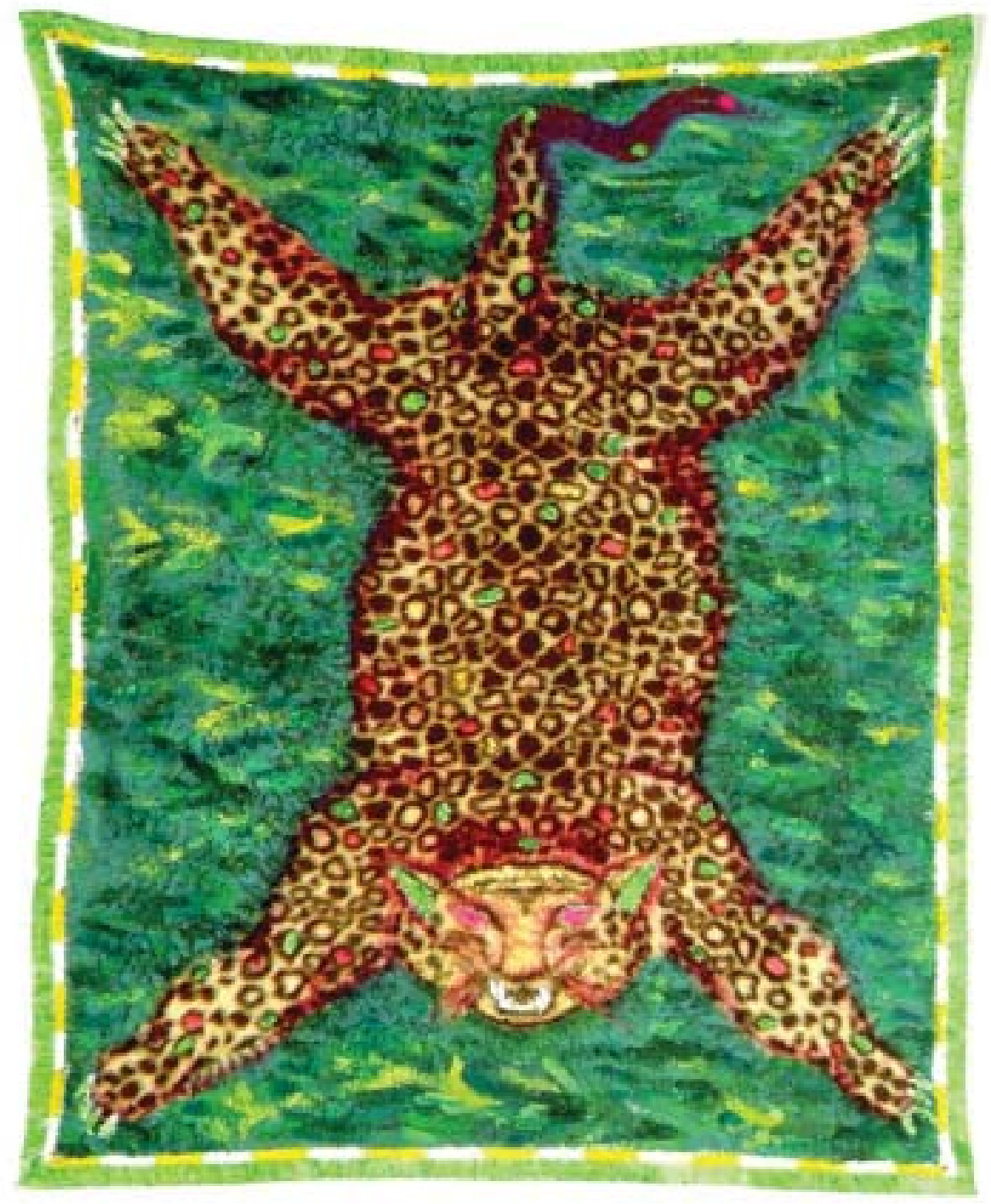

Leda CATUNDA (São Paulo, SP, 1962), Onça pintada nº 1, 1984.

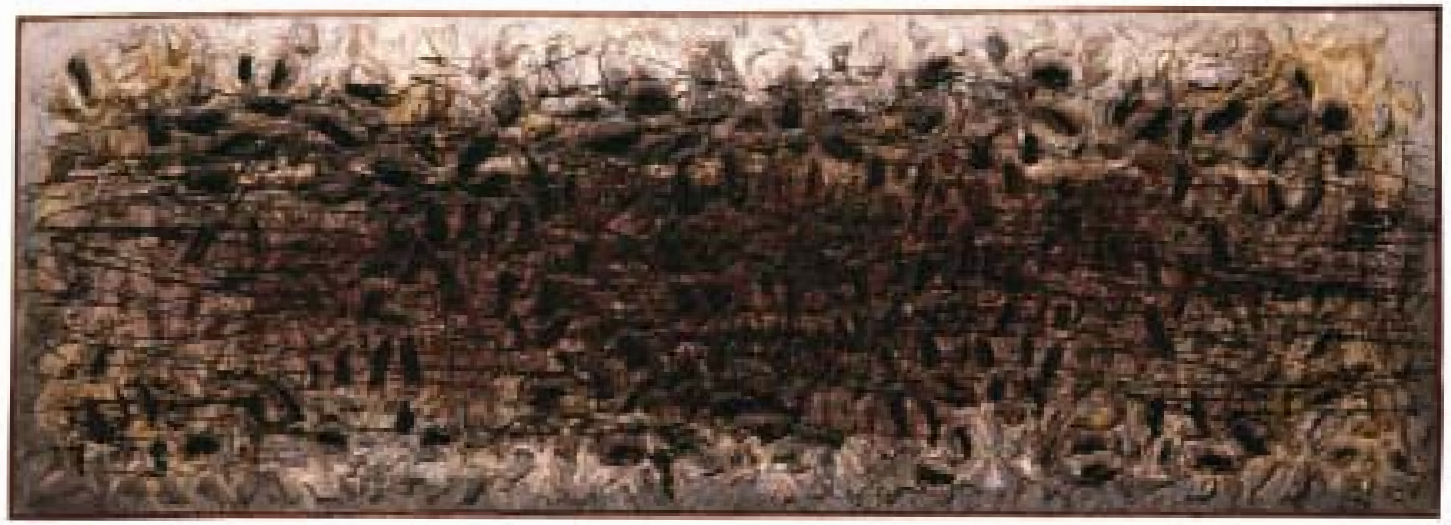

Frans KRAJCBERG (Kozienice, Polônia, 1921), Relevo nํ 1, 1960.

Estudos AvanÇAdos 19 (55), 2005 


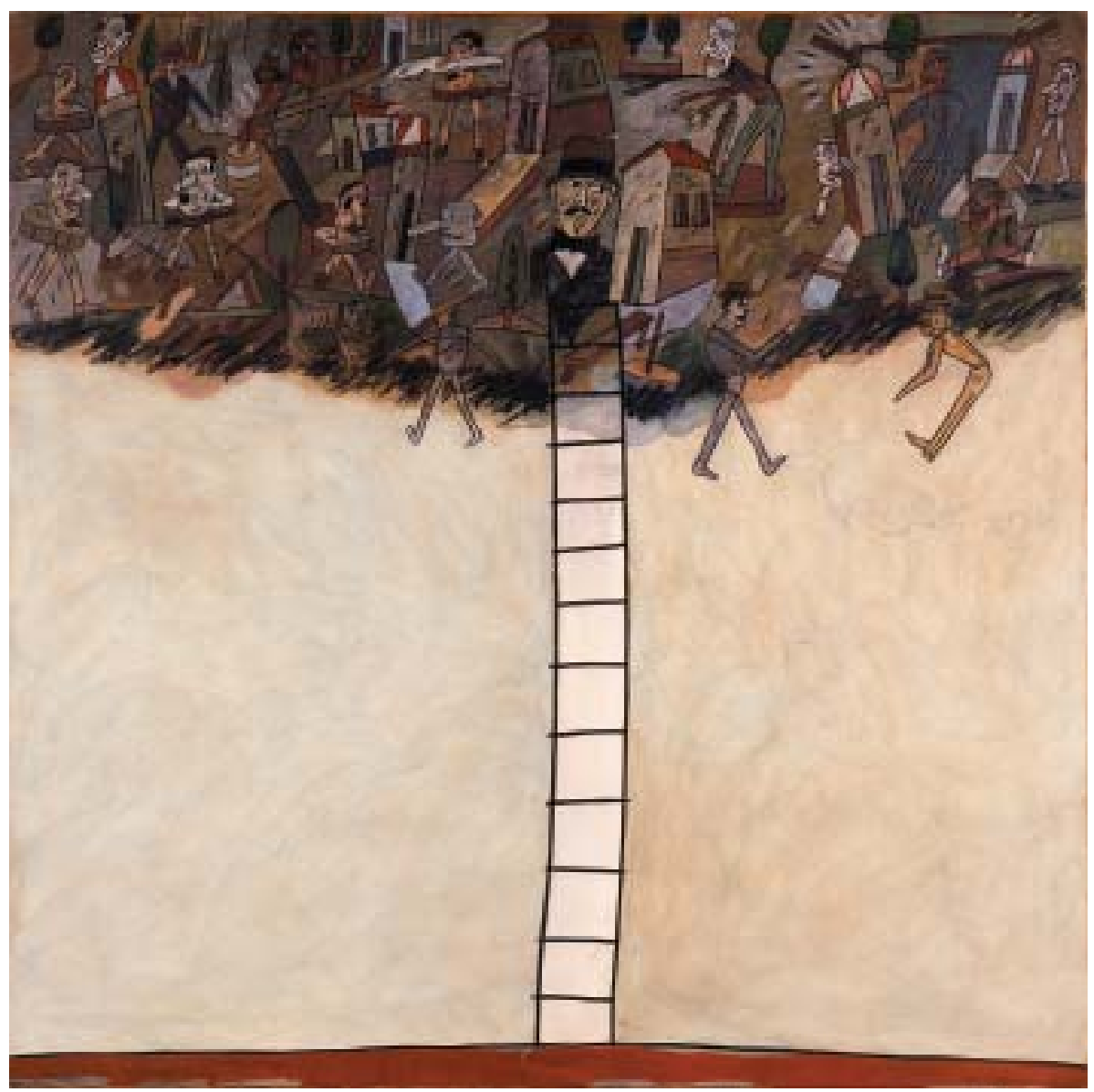

Antonio SEGUI (Córdoba, Argentina, 1934), Difícil de subir, 1984.

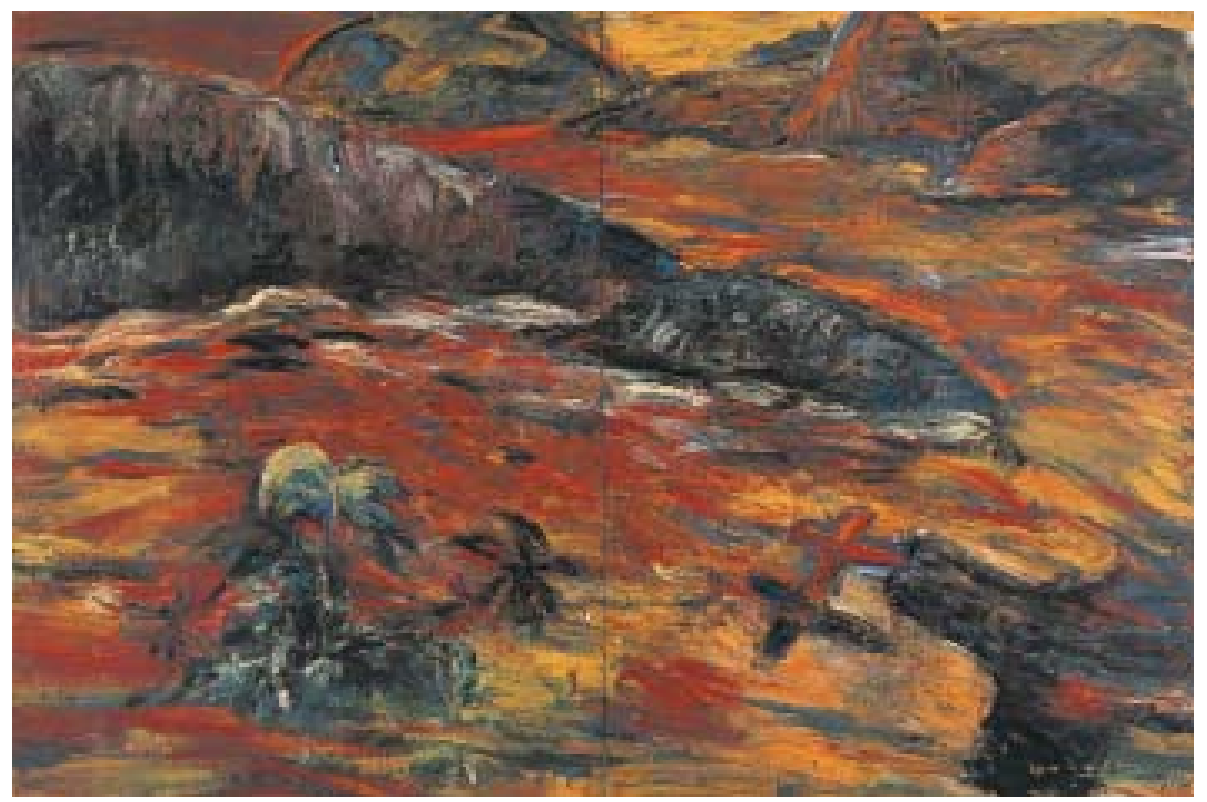

Cristina CANALE (Rio de Janeiro, RJ, 1961), Rio 40º 1987. 


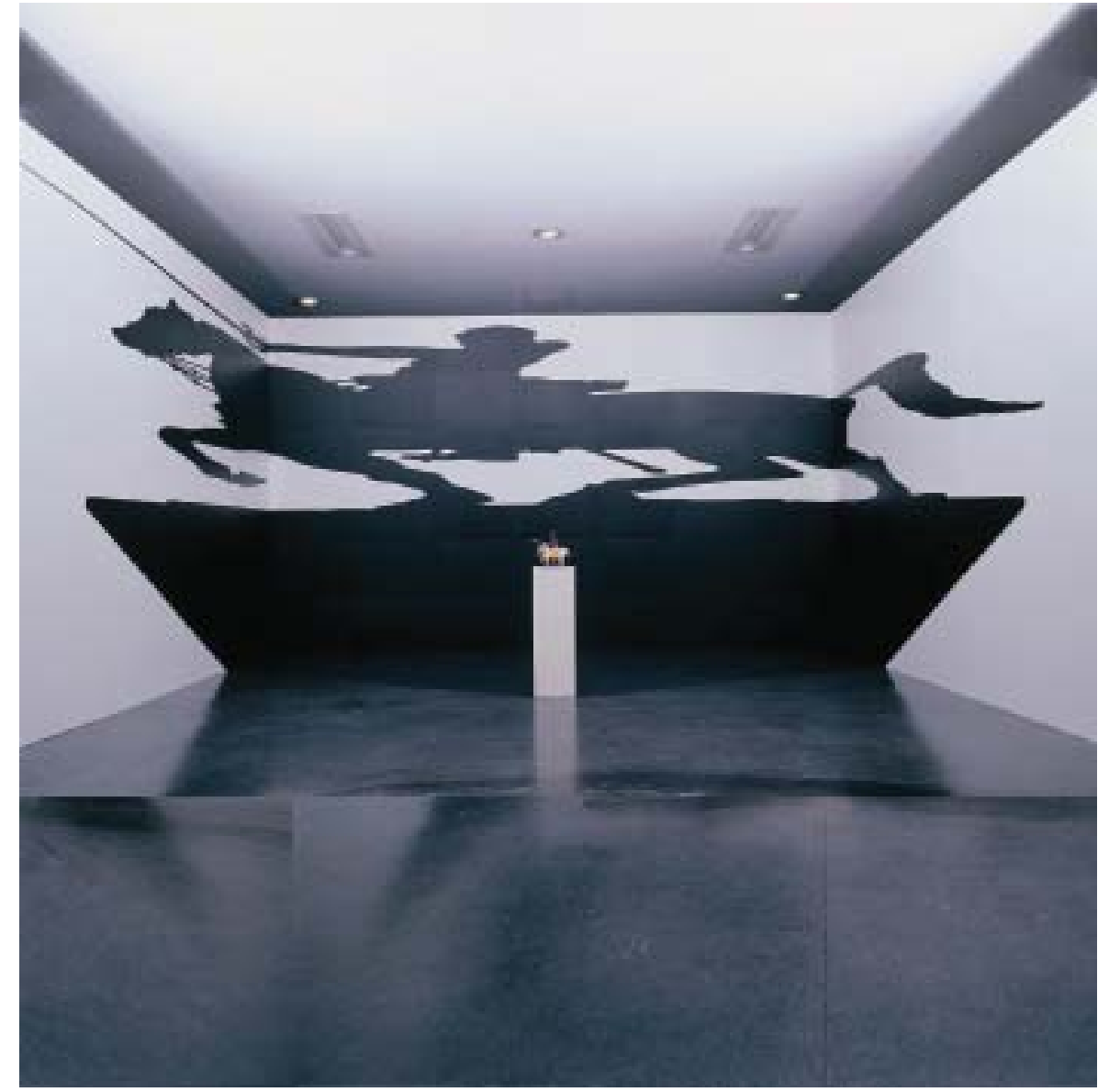

Regina SILVEIRA (Porto Alegre, RS, 1939), Paradoxo do santo, 1994.

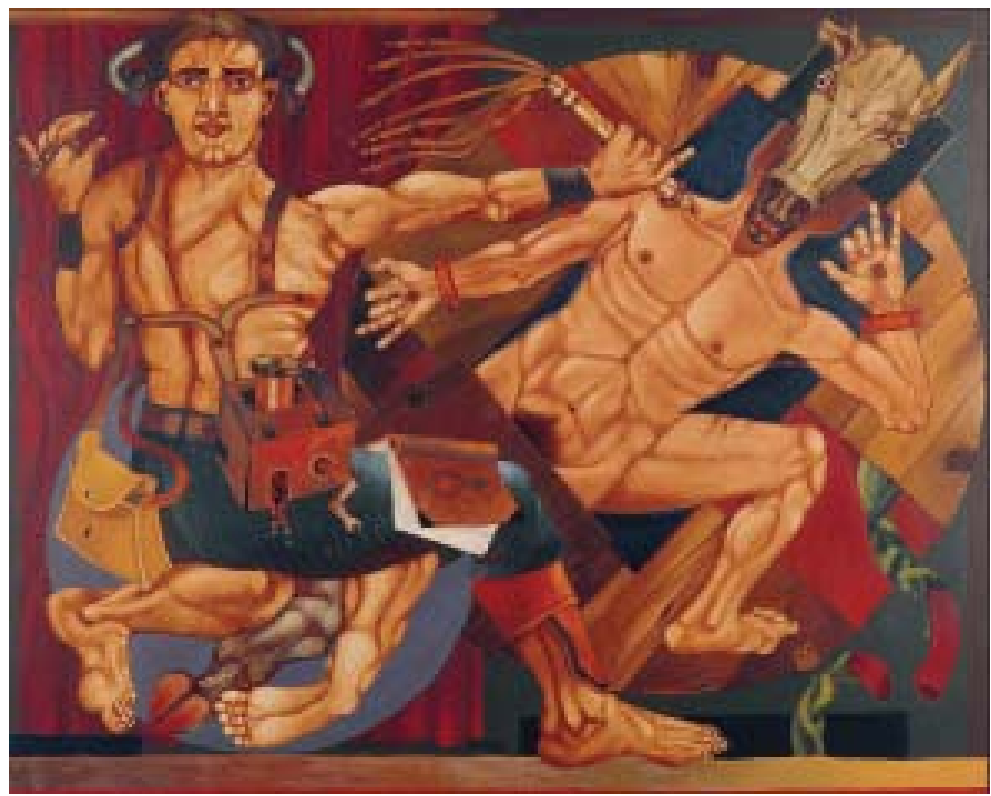

João CÂMARA F. (João Pessoa, PB, 1944), Uma confissão, 1971. 


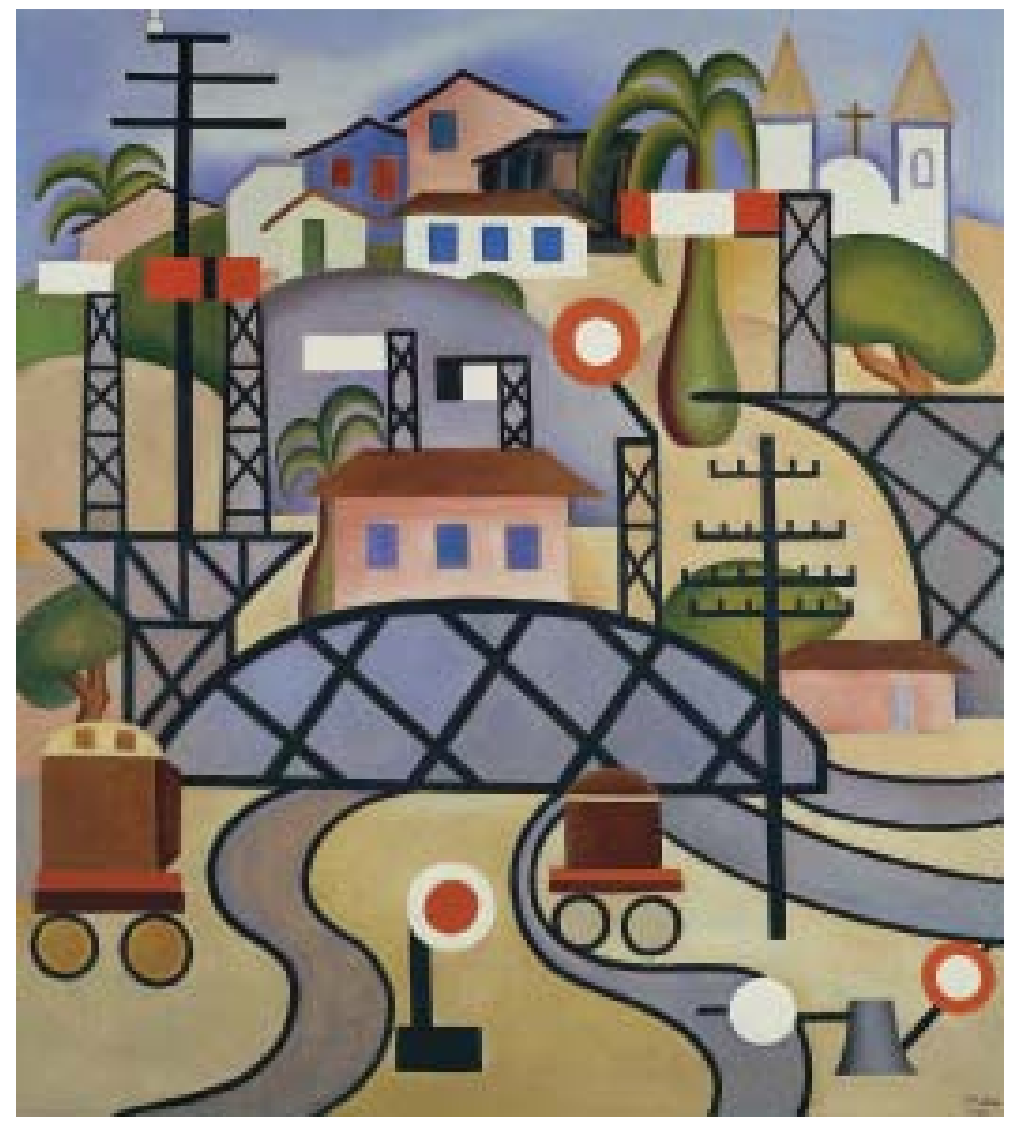

Tarsila do AMARAL, Estrada de Ferro Central do Brasil, 1924.

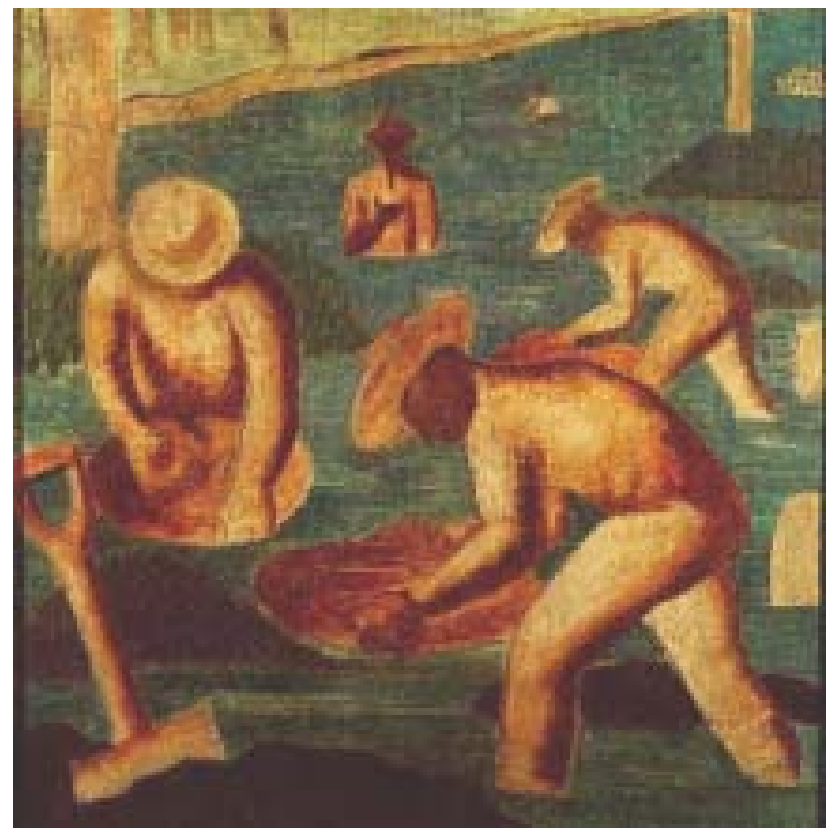

Cândido PORTINARI, Mineradores, c. 1941. 